\title{
Mortality in ulcerative colitis
}

\author{
B D George
}

Correspondence to

B George, Radcliffe Infirmary, Department of Colorectal

Surgery, John Radcliffe

Hospital, Oxford OX3 9DU, UK;

brucegeorge@

doctors.org.uk
The study by Falvey and colleagues ${ }^{1}$ is a useful one which adds to our understanding of the natural history of patients requiring admission to hospital for treatment of ulcerative colitis (UC) (see page 35). The major findings of the study are:

(1) Three year mortality after admission for treatment of UC is $5.7 \%$.

(2) Patients who died were older and had greater comorbidity.

(3) Surgical mortality was zero (although one older patient with comorbidity died while awaiting colectomy).

This is a small study but is representative of what might be expected in a high quality inflammatory bowel disease (IBD) practice in the UK. The findings challenge some of the messages from the recent epidemiological study by Roberts and colleagues. ${ }^{2}$ Roberts et al looked at large cohorts of patients in the Oxford region from 1968 to 1996 and in England from 1998 to 2000. Patients who had been admitted to hospital and coded as having IBD as the main diagnosis were identified from hospital discharge abstracts. UC and Crohn's disease were analysed separately. The dominant findings of their study were:

(1) Overall mortality after admission with UC was $12.2 \%$ after 3 years.

(2) Mortality after emergency colectomy was $13.2 \%$ after 3 years.

(3) Mortality after admission for UC, but no surgery, was $13.6 \%$ after 3 years.

(4) Patients undergoing elective colectomy had a mortality of $3.7 \%$ after 3 years.

Although the methodology was different, the two studies aimed to assess similar patients. The overall mortality at 3 years $(5.7 \%$ vs $12.2 \%)$ however was markedly different. Falvey's study suggests that this difference is principally due to many patients initially thought to have UC actually having a different diagnosis (table 2 of Falvey's paper ${ }^{1}$ ). Falvey et al excluded this group of patients $(44 \%, 82$ of 188) in their analysis. If these patients had been included, the 3 year mortality values would have been very similar in the two studies (11.2\% and $12.2 \%)$. The Falvey study therefore represents a more meaningful value for patients with UC.

The second finding that patients who died were older and had greater comorbidity than those who survived is intuitive and not surprising. The third finding of a zero operative mortality in patients who required colectomy is impressive but may reflect a relatively small study and is not matched in national data. The UK IBD audit (second round) and a national study from Canada reported early postcolectomy mortalities of $2.9 \%$ and $2.3 \%$, respectively. ${ }^{34}$

Although mortality from surgery for UC may be low, morbidity is significant. A recently published study of 80 patients from Oxford undergoing colectomy for acute severe UC and followed for a median of 5.4 years reported a zero operative mortality, 4\% (3/80) mortality at 5 years (from unrelated diseases) but a significant cumulative morbidity of $60 \% .5$

How do Falvey et al's and other recent studies help us in talking to patients admitted with UC who are facing possible colectomy? Firstly, the 3 year risk of death in patients admitted to hospital with proven UC is less than suggested by Roberts and colleagues' study. Furthermore, the risk of death is related more to age and comorbidity than to UC. However, it should be clearly explained that although the mortality of surgery is low, morbidity is high.

Reducing mortality and morbidity may be achieved by a variety of means. Roberts' study emphasises that emergency colectomy is more hazardous than elective colectomy. However, the dangers of delayed colectomy must be recognised. Data from our own study ${ }^{5}$ and from Kaplan et al ${ }^{4}$ indicate that delayed colectomy is significantly associated with increased morbidity and mortality, respectively. Recent advances 
in medical and surgical treatment of UC, notably the use of infliximab and laparoscopic colectomy, will hopefully contribute to improved outcomes. The UK IBD audit has highlighted variations in use of both of these approaches. ${ }^{3}$ The impact of infliximab therapy on the timing and risks of surgery is controversial. ${ }^{67}$ Laparoscopic colectomy is undertaken in about $10 \%$ of patients in the $\mathrm{UK}^{3}$ although recent evidence suggests better short term outcomes. ${ }^{8}$ Long term results after laparoscopic procedures for UC are not available.

The optimum management of UC requiring treatment in hospital still remains a challenge for physicians and surgeons. A new national study of medical rescue therapy for acute severe colitis (ciclosporin vs infliximabCONSTRUCT study) is shortly to be undertaken. This will inform medical decision making in the future. For patients facing surgery today, the message is one of improving mortalities. However, emerging evidence still suggests significant surgical morbidity, particularly if time to colectomy is delayed.

\section{Competing interests None.}

Provenance and peer review Commissioned; not externally peer reviewed.

\section{References}

1. Falvey JD, Greenwood R, Creed TJ, et al. Mortality in ulcerative colitis-what should we tell our patients? Three year mortality following admission for the treatment of ulcerative colitis: a 6 year retrospective case review. Frontline Gastroenterol 2010;1: $35-41$.

2. Roberts SE, Williams JG, Yeates D, et al. Mortality in patients with and without colectomy admitted to hospital for ulcerative colitis and Crohn's disease: record linkage studies. BMJ 2007;335;1033.

3. UK IBD Audit 2nd Round (2008) Report. http://www.rcplondon.ac.uk/clinicalstandards/ceeu/Current-work/IBD/Pages/AuditWork-Programme.aspx (accessed 28 January 2010).

4. Kaplan GG, McCarthy EP, Ayanian JZ, et al. Impact of hospital volume on postoperative morbidity and mortality following a colectomy for ulcerative colitis. Gastroenterology 2008;134:680-7.

5. Randal J, Singh B, Warren B F, et al. Delayed surgery for acute severe colitis is associated with increased risk of postoperative complications. Br J Surg Epub ahead of print: 25 January 2010 (doi: 10.1002/bjs.6874).

6. Mor IJ, Vogel JD, Moreira Ada L, et al. Infliximab in ulcerative colitis is associated with an increased risk of postoperative complications after restorative proctocolectomy. Dis Colon Rectum 2008;51:1202-10.

7. Kunitake H, Hodin R, Shellito P, et al. Perioperative treatment with infliximab (IFX) in patients with Crohn's (CD) and ulcerative colitis (UC) is not associated with increased rate of postoperative complications. J Gastrointestinal Surg 2008;12:1730-6.

8. Marceau C, Alves A, Ouaissi M, et al. Laparoscopic subtotal colectomy for acute or severe colitis complicating inflammatory bowel disease: a case-matched study in 88 patients. Surgery 2007;141:640-4. 